\title{
Sugar alcohols
}

National Diabetes Information Clearinghouse (NDIC)

\section{Definitions}

Blood glucose

Defined by National Diabetes Information Clearinghouse (NDIC)

Carbohydrate

Defined by National Diabetes Information Clearinghouse (NDIC)

\section{Calorie}

Defined by National Diabetes Information Clearinghouse (NDIC)

Gram

Defined by National Diabetes Information Clearinghouse (NDIC)

Xylitol

Defined by National Diabetes Information Clearinghouse (NDIC)

\section{Source}

National Diabetes Information Clearinghouse (U.S.). (2009). The diabetes dictionary. [Bethesda, Md.]: U.S. Dept. of Health and Human Services, National Institutes of Health, National Institute of Diabetes and Digestive and Kidney Diseases, National Diabetes Information Clearinghouse.

Sweeteners that produce a smaller rise in blood glucose than other carbohydrates. Their calorie content is about 2 calories per gram. Includes erythritol, hydrogenated starch hydrolysates, isomalt, lactitol, maltitol, mannitol, sorbitol, and xylitol. Also known as polyols. 